\title{
IZAZOVI I DOMETI REVIZIJE PRIHODA
}

\author{
Bojan Savić \\ Univerzitet u Beogradu, Poljoprivredni fakultet, Zemun \\ Ivan Milojević \\ Univerzitet odbrane u Beogradu, Vojna akademija
}

Drihodi predstavljaju jedan od tokova rentabiliteta, a time i ključnu determinantu obračuna uspeha entiteta. Zbog svog značaja prihodi su nezaobilazna pozicija koja podleže reviziji od strane ovlašćenog revizora. Kompleksnost primene Međunarodnog standarda finansijskog izveštavanja 15 - Prihodi od ugovora sa kupcima kao i drugih MSFI koji tretiraju problematiku priznavanja, merenja i obelodanjivanja prihoda, aktuelne izmene Međunarodnih standarda revizije, zajedno sa visokim stepenom rizika od manipulacija prihodima, čini reviziju navedene pozicije veoma delikatnim pitanjem. Cilj rada je da ukaže na ključne izazove sa kojima se revizor suočava prilikom sprovođenja revizije prihoda, kao i specifične procedure koje se tom prilikom sprovode.

Ključne reči: prihodi, Međunarodni standardi revizije, Međunarodni standardi finansijskog izveštavanja

\section{Uvod}

$U$ savremenim uslovima poslovanja nezavisna revizija predstavlja jedan od centralnih stubova efikasnosti i stabilnosti finansijskog tržišta, kao ključne pretpostavke optimalne alokacije resursa, sigurnosti investiranja i nesmetanog odvijanja privrednih tokova. Svrha revizije kao nezavisne i stručne verifikacije jeste da utvrdi stepen u kome prikazane finansijske informacije odgovaraju realnosti. odnosno revizor treba da utvrdi da li su finansijski izveštaji oslobođeni materijalno značajnih grešaka (pogrešnih iznosa) i nepravilnosti. Postizanje zahtevanog kvaliteta finansijskih izveštaja pretpostavlja adekvatnu primenu MSFI i opšteprihvaćenih računovodstvenih principa od strane sastavljača finansijskih izveštaja. Da bi primarni korisnici imali poverenje u finansijske izveštaje i na bazi njih donosili odgovarajuće odluke o alokaciji kapitala, neophodno je da kvalitet sprovedene revizije bude na visokom nivou.

Kroz nezavisno ispitivanje računovodstvenih iskaza u cilju izvođenja zaključaka i formiranja mišljenja o tome da li su u finansijskim izveštajima objektivno i tačno prikazane pozicije imovine, obaveza, kapitala, prihoda i rashoda, revizori utiču na ponašanje učesnika u jednoj privredi. Naime, kvalitet finansijskih izveštaja predmet je posebne pažnje postojećih i potencijalnih investitora, kreditora, poslovnih partnera, fiskusa. Ono što im je svima zajedničko jeste interesovanje za kvalitet prikazanih informacija o prihodima budući da je reč o poziciji koja neposredno utiče na visinu ostvarenog rezultata. 
Ukoliko informacije o prihodima ne odgovaraju realnosti, brojne odluke o alokaciji kapitala biće pogrešne, što dalje dovodi do neoptimalne alokacije resursa i nastanka problema u jednoj privredi. Otuda su predmet revizije ne samo finansijski izveštaji, već i dokumentacija koja predstavljaju ishodište i potporu za računovodstvenu evidenciju, kao i metode koje su primenjene prilikom njihovog procesiranja. Dodatno, u cilju izvođenja odgovarajućeg mišljenja o prikazanim informacijama revizor mora testirati celokupan računovodstveni i upravljački informacioni sistem, kao i sistem interne kontrole (način funkcionisanja fakturisanja, ovlašćenje lica koja odobravaju popuste kupcima i drugo). Kroz proces planiranja i prikupljanja adekvatnih dokaza revizor kreira osnovu za izvođenje mišljenja o prikazanim informacijama.

MSFI 15 - Prihodi od ugovora sa kupcima uveden je sa ciljem da se unaprede smernice za priznavanje prihoda. Smatra se da će navedeni standard (primena otpočela 01.01.2018.) imati značajne implikacije na priznavanje prihoda entiteta u oblasti telekomunikacija, vazduhoplovstva, odbrane, tehnologije, nekretnina, automobilske industrije, softverskih proizvoda, intelektualne svojine, licencama i drugo. Sa uvođenjem navedenog standarda računovodstveno obuhvatanje pozicije prihoda postalo je izuzetno kompleksno. Pri tome, neadekvatna primena navedenog standarda može usloviti pojavu upozoravajućih signala u pogledu visine iskazanog prihoda, a time i rezultata, dovesti do kašnjenja u obelodanjivanju finansijskih izveštaja, usloviti izražavanje kvalifikovanog mišljenja revizora, narušiti poverenje investitora i konačno, usloviti pad tržišne cene akcija.

Cilj rada je da ukaže na ključne izazove koji se javljaju prilikom revizije pozicije prihoda odnosno planiranja i izvođenja procedura usmerenih na pribavljanje dokaza i formiranje zaključaka o kvalitetu prikazanih informacija.

\section{Specifičnosti revizije prihoda}

Prema svom karakteru i iznosu prihodi predstavljaju značajnu poziciju u Izveštaju o uspehu. Značaj navedene računovodstvene kategorije proizilazi iz potrebe da se obuvati pozitivan tok rentabiliteta za određeni vremenski period i da se kao takav sučelji sa negativnim tokom rentabiliteta (rashodima), u cilju obračuna periodičnog rezultata. U najvećem broju entiteta navedeni tok nastaje prevashodno realizacijom učinaka (proizvoda i usluga). U Konceptualnom okviru za finansijsko izveštavanje prihodi se definišu kao povećanje ekonomske koristi u toku obračunskog perioda u obliku priliva ili povećanja imovine ili smanjenja obaveza, što konačno rezultira povećanjem sopstvenog kapitala. Pozicije prihoda obuhvataju prihode iz redovnog poslovanja (na primer, po osnovu prodaje, kamate, dividende, provizije, zakupnina i drugo), kao i dobitke koji se po svojoj prirodi ne razlikuju od prihoda, a nastaju po osnovu unovčenja (prodaje) imovine entiteta. Prihodi takođe mogu nastati i po osnovu revalorizacije odnosno povećanja fer vrednosti određene pozicije imovine. Konačno, nastanak prihoda moguć je i po osnovu izmirenja obaveza, u slučaju kada se zajmodavcu vrši isporuka robe i usluga radi izmirenja nastale obaveze, ali i u slučaju zastarevanja ili oprosta obaveza od strane poverioca, kada se javljaju ostali prihodi (Mirza \& Holt, 2011).

Neophodno je takođe ukazati na razliku između prihoda i priliva novca. Priliv se odnosi na uplate novca i tangira saldo gotovine (tekućeg računa), dok se prihodima tangira visina neto imovine tj. sopstvenog kapitala. Tokovi novca (prilivi i odlivi) relevantni su za 
praćenje likvidnosti, dok prihodi predstavljaju sastavni deo toka rentabiliteta. Po pravilu, postoji vremenska nepodudarnost između nastanka prihoda i priliva novca. Za priznavanje prihoda merodavan je princip realizacije. U pitanju je zahtev da se prihod priznaje u Izveštaju o uspehu tek kada je tržišno verifikovan odnosno potvrđen kroz kupoprodajni akt. Značaj principa realizacije ogleda se u prepoznavanju trenutka kada se prihod može smatrati realizovanim (vremenski aspekt), kao i visine prihoda ostvarenog u određenom obračunskom periodu (vrednosni aspekt). To je od posebnog značaja za ocenu kvaliteta finansijskih informacija, odnosno izražavanje mišljenja o tome da li su finansijski izveštaji oslobođeni od materijalno značajnih grešaka i nepravilnosti. Smatra se da prihode treba priznati u obračunskom periodu kada je učinak proizveden i tržišno verifikovan, u visini prodajne vrednosti realizovanih učinaka (Ranković, 2016).

Finansijski i ostali prihodi takođe predstavljaju značajnu komponentu ukupnih prihoda. Finansijski prihodi nastaju po osnovu redovnih kamata na kratkoročne i dugoročne plasmane, primljene menice od kupaca, iskorišćenih ugovorenih kasa-skonta u slučaju izmirenja obaveza prema dobavljačima pre roka dospeća, pozitivnih kursnih razlika na potraživanja i obaveze ugovorene u stranim sredstvima plaćanja, zatezne kamate koje se zaračunavaju kupcima i drugim dužnicima zbog kašnjenja u isplati. Ostali prihodi nisu neposredno povezani sa tekućom aktivnošću preduzeća. Javljaju se kao posledica povoljnih okolnosti i slučajnosti. Primeri se odnose na viškove obrtne imovine utvrđene inventarom, naplatu otpisanih potraživanja, obračunate i naplaćene penale i kazne i drugo (Škarić, 2013).

Priroda poslovanja posmatranog entiteta opredeljuje ključne izvore prihoda, kao i povezane rashode koji nastaju generisanjem prihoda. Otuda je neophodno da revizor dobro poznaje i razume poslovanje klijenta kako bi bio u mogućnosti da na adekvatan način izvrši reviziju pozicije prihoda. S obzirom na organsku povezanost Izveštaja o finansijskom položaju i Izveštaja o uspehu (prihodi se manifestuju kao povećanje aktive i smanjenje obaveza) u postupku sprovođenja revizije postoji paralela između verifikacije pojedinih pozicija aktive i pasive s jedne, i verifikacije prihoda sa druge strane.

Ciljevi revizije transakcija prihoda i povezanih računa izvode se iz tvrdnji menadžmenta. S tim u vezi, revizor treba da kroz prizmu osnovnih tvrdnji menadžmenta ispita adekvatnost računovodstvenog obuhvatanja prihoda (Puttick, Van Esch, Van Esch, \& Kana, 2007):

Tvrdnja potpunosti - cilj revizije je da ustanovi da li su svi prihodi koji su prikazani u posmatranom periodu zaista i nastali, da li je gotovina primljena u toku perioda kada je priznavanje prihoda izvršeno, da li su sve korekcije koje se odnose na pozicije prihoda proknjižene (na primer, po osnovu povrata robe, otpisa potraživanja i slično).

Tvrdnja nastanak - u vezi navedene tvrdnje menadžmenta revizor mora proveriti da li je priznavanje prihoda praćeno isporukama dobara tokom perioda, kao i da li se proknjiženo primanje gotovine zaista odnosi na posmatrani period.

Postojanje - neophodno je da revizor proveri da li računi potraživanja na kraju godine zaista postoje.

Vrednovanje i alokacija - revizor mora utvrditi da li su pozicije potraživanja u odgovarajućem iznosu uključene u Izveštaj o finansijskom položaju, kao i da li su svi otpisi i korekcije potraživanja i prihoda izvršeni na odgovarajući način.

Prava i obaveze - u vezi navedene tvrdnje revizor mora istražiti da li iznos potraživanja reprezentuje validne pravne zahteve za naplatu koje entitet ima prema dužnicima na izveštajni datum, kao i da li se prava poverioca u pogledu računa potraživanja mogu jasno identifikovati. 
Prikazivanje i obelodanjivanje - neophodno je proveriti da li su obelodanjivanja neto prihoda entiteta izvršena u skladu sa MSFI, kao i da li su računi potraživanja u finansijskim izveštajima adekvatno prikazani i klasifikovani.

Tačnost i klasifikacija - revizor istražuje da li su prihodi, gotovina i korekcije prihoda obračunati u skladu sa načelom istinitosti i obuhvaćeni saglasno računovodstvenim politikama definisanim pojedinim MSFI, kao i da li su prikazani na odgovarajućim računima.

Razgraničenje - verifikacija navedene tvrdnje pretpostavlja da revizor ustanovi da li su prihodi, gotovina i korekcije prihoda izvršene u korektnim računovodstvenim periodima.

Većina računa prihoda verifikuje se od strane revizora prilikom ispitivanja računa aktive i pasive (potraživanja od kupaca, finansijski plasmani - prihodi od kamata, dugoročna učešća - dividende, hartije od vrednosti - kamate i dividende, investicione nekretnine prihodi od zakupnina, postrojenje i oprema - dobici od prodaje, biološka imovina - prihodi od usklađivanja vrednosti u slučaju povećanja fer vrednosti i slično).

\section{Verifikacija prihoda iz perspektive interne revizije}

Eksterni revizor se u svom radu u značajnoj meri oslanja na rad interne revizije. Kada je reč o reviziji pozicija prihoda akcenat je na ispitivanju interne kontrole i testiranje transakcija, što znači da najveći deo posla revizor sprovodi pre kraja obračunskog perioda. Cilj revizije prihoda je da se prouči i oceni sistem interne kontrole u domenu računovodstvenog obuhvatanja i knjiženja prihoda, zatim proveri da li su svi nastali prihodi proknjiženi i da li su svi proknjiženi prihodi zaista nastali, i konačno, da se utvrde tendencije u kretanju prihoda i istraže značajnije fluktuacije iznosa pojedinih kategorija prihoda (Martić, 1993).

Svoj rad interni revizori započinju prikupljanjem i analizom informacija sa tržišta, kako bi se ocenila efektivnost proizvodnje u odnosu na tržišne zahteve. Težište aktivnosti interne revizije treba da bude istraživanje tržišne tražnje, istraživanje proizvoda, distribucije, cena i drugo. Ispitivanje prihoda treba da se zasniva na izvršenju proizvodnog plana, a u slučaju kada preduzeće ima širi proizvodni asortiman neophodno je sprovesti detaljniju analizu izvršenja proizvodnog plana po asortimanu. Eventualna negativna odstupanja između planiranih i ostvarenih veličina ukazuju na neefikasno odlučivanje i poslovanje. Cilj interne revizije jeste unapređenje poslovanja i kreiranje vrednosti (Milojević, 2006). Dodatno, interna revizija ima savetodavnu ulogu, a područje se prostire od ocene kvaliteta finansijskih izveštaja, preko provere i ocene efikasnosti i efektivnosti poslovanja, sve do utvrđivanja ekonomičnosti poslovnih poduhvata (Novaković Jovićević, \& Simin, 2018).

S obzirom na značaj pozicije prihoda, transakcije koje generišu prihod neophodno je pratiti brojnim formalnim kontrolnim aktivnostima radi efikasnijeg upravljanja poslovnim rizikom. S tim u vezi, revizor će testirati efektivnost internih kontrola kako bi redukovao kontrolni i inherentni rizik. Procena adekvatnosti interne kontrole prihoda obuhvata sledeće elemente: mesto kontrole, računovodstvene metode koje se koriste za obradu transakcija, kao i kontrolne procedure koje se odnose na davanje ovlašćenja za izvršenje i evidentiranje transakcija (Andrić, Krsmanović, \& Jakšić, 2004).

Takođe, neophodno je ispitati zakonitost odnosno da li je preduzeće respektovalo zakonske propise prilikom realizacije plana prihoda, odnosno da li je poslovalo saglasno principima dobre poslovne prakse. Jedna od stavki verifikacije prihoda jesu i prodajne 
cene. Zadatak interne revizije u ovom segmentu jeste da proveri da li prodajne cene po kojima su realizovanu učinci odgovaraju planiranim iznosima. U slučaju eventualnih odstupanja potrebno je ispitati uzroke i uticaj navedenih promena na ostvarene prihode. Uslovi pod kojima je prodaja izvršena takođe je sastavni deo istraživanja interne revizije. Ovde se pre svega misli na kreditne uslove, rokove plaćanja, odobrene popuste, način obezbeđenja plaćanja. Navedeni elementi utiču na visinu ostvarenih prihoda. Takođe, neophodno je utvrditi da li su uslovi prodaje u proteklom obračunskom periodu promenjeni kao i razloge eventualnih promena (Johnstone, Gramling \& Rittenberg, 2013).

Kada je reč o finansijskim i ostalim prihodima, oni takođe moraju biti predmet ispitivanja, s obzirom da u određenim obračunskim periodima mogu imati značajno učešće u ukupnim prihodima a u određenim slučajevima mogu opredeliti predznak periodičnog rezultata. Interni revizor treba da utvrdi opravdanost pojave kategorije Ostali prihodi kao i rizike da će u nastupajućim obračunskim periodima postati problematični. Na primer, ukoliko se utvrđeni viškovi materijala, gotovih proizvoda i drugih stavki bez detaljnijeg istraživanja priznaju u okviru pozicije Ostali prihodi, to može biti signal da se u preduzeću ne preduzimaju koraci za utvrđivanje uzroka pojave navedenih viškova.

Revizor treba da oceni interne kontrole povezane sa prihodima, a posebno sisteme i procedure povezane sa generisanjem prihoda, kao i ovlašćenje za definisanje cena, popusta, i drugih uslova prodaje, zatim računovodstvene procedure povezane sa priznavanjem prihoda, kao i postojanje periodičnih izveštaja o ostvarenim performansama u odnosu na planirane. Verifikacija prihoda se odnosi na procedure knjiženja i primenjene analitičke procedure. Istraživanje knjiženja odnosi se na utvrđivanje da li je osnova za priznavanje prihoda u skladu sa računovodstvenim principima, zatim adekvatnost i efikasnost procedura razgraničenja prodaje i povrata prodaje. Revizor mora ustanoviti da li navedene transakcije pripadaju periodu za koji su prikazane, a ne prethodnom ili narednom obračunskom periodu, Takođe, revizor treba da ispita lansiranje dokumentacije koje je sprovedeno pred kraj poslovne godine i proveri da li su prodajne fakture obuhvaćene u periodu koji je predmet revizije. Predmet ispitivanja moraju biti i izabrane stavke prodaje kroz njihovo uparivanje sa fakturama, a takođe je neophodno istražiti i prateću dokumentaciju kao što su narudžbenice kupaca, zatim da uporedi stvarnu cenu sa odobrenom cenom i drugo (Gupta, 2006).

Preliminarne analitičke procedure usmerene na ispitivanje prihoda obuhvataju komparaciju (Gupta, 2006):

- Iznosa prihoda iz tekućeg perioda po pojedinim proizvodima i lokacijama sa iznosima iz prethodnih perioda;

- Stope bruto marže sa prihodima od prodaje tekuće godine i podacima iz prethodnih godina;

- Stope povrata prodaje sa prodajom tekućeg perioda i podataka za prethodne godine;

- Podataka o odobrenim diskontima za tekuću godinu sa povezanim podacima u prethodim periodima;

- Količinskog obima prodaje u tekućem periodu po proizvodima i lokacijama za tekuću i prethodne godine;

- Prihoda po osnovu dividendi, kamata, tantijema, za tekuću i prethodne godine.

Ukoliko se na osnovu preliminarnih testova ustanovi da je neophodno sprovesti i postupke suštinskih provera u cilju pribavljanja dokaza, tada revizor treba da oceni da li su transakcije prodaje adekvatno vrednovane, da li postoje računi potraživanja, da li su 
sprovedena otpisivanja potraživanja opravdana i da li su finansijski izveštaji lišeni manipulacija i pronevera (Johnstone, Gramling, \& Rittenberg, 2013).

U nastavku rada predmet razmatranja će biti računovodstveno obuhvatanje prihoda u skladu sa MSFI 15 - Prihodi od ugovora sa kupcima, kao i revizorske procedure čije sprovođenje traba da omogući verifikaciju navedenih stavki prihoda.

\section{Revizija prihoda obuhvaćenih u skladu sa MSFI 15 - Prihodi od ugovora sa kupcima}

MSFI 15 - Prihodi od ugovora sa kupcima pruža smernice za priznavanje i merenje prihoda kroz sledeći model (Chartered Professional Accountants Canada, 2015; Nešić, 2017):

\section{Identifikovati ugovor sa kupcima}

Ugovor postoji ukoliko su uključene strane prihvatile ugovor, prava i obaveze svih strana se mogu jasno identifikovati, moguće je utvrditi uslove i rokove plaćanja za prenos dobara i usluga, ugovor ima komercijalni karakter i očekuje se naplata naknade za preneta dobra i izvršene usluge. Ako navedeni uslovi nisu ispunjeni prihod se može priznati samo ukoliko entitet nema neizvršene obaveze u pogledu isporuke dobara (svojina i rizici preneti na kupca) i pružanja usluga ili ako je ugovor raskinut, a primljena naknada od klijenta ima nepovratni karakter.

\section{Utvrditi obaveze iz ugovora}

U pitanju su obaveze po osnovu isporuke jednog ili više dobara/usluga, odnosno niza identičnih dobara ili usluga koji se prenose na isti način. U ovom slučaju entitet mora odrediti da li će obavezu izvršenja obuhvatiti pojedinačno ili grupno.

\section{Odrediti cenu transakcije}

Cena transakcije je iznos koji će entitet primiti u zameni za prenos dobara i pružanje usluga, pri čemu se ne uključuje iznos koji je naplaćen u korist trećih lica (porez). Faktori koji utiću na cenu transakcije obuhvataju varijabilnu naknadu (variranje je moguće zbog odobrenih popusta, kasa-skonta, količinskog rabata i drugo), vremenska vrednost novca u slučaju finansiranja kupaca, negotovinska naknada, naknada koja se plaća kupcu (odobravanje kupona, vaučera i slično, čime se redukuje cena transakcije).

\section{Alocirati transakcione cene na obaveze iz ugovora}

Cenu transakcije neophodno je dodeliti svakoj pojedinačnoj obavezi sadržanoj u ugovoru. Najbolji dokaz pojedinačne cene jeste redovna prodajna cena po kojoj entitet fakturiše određeno dobro drugim kupcima u sličnim okolnostima. Ako pojedinačnu prodajnu 
cenu nije moguće utvrditi Standard predlaže procenjivanje prodajne cene primenom jedne od sledećih metoda: korigovana tržišna cena, očekivani troškovi uvećani za maržu ili na bazi rezidualnog pristupa.

\section{Izvršiti priznavanje prihoda kada entitet ispuni obaveze iz ugovora}

Prenos kontrole sa prodavca na kupca može se izvršiti tokom vremena kada je reč o odloženom prihodu ili u određenom trenutku (prenos fizičkog poseda imovine na kupca, prenos rizika i koristi, prihvatanje imovine od strane kupca i slično).

Namera Međunarodnog odbora za računovodstvene standarde je da se kroz navedeni model omogući prikazivanje korisnih informacija o vrsti, iznosu, riziku i vremenskom rasporedu prihoda i novčanih tokova koji proizilaze iz ugovora zaključenih sa klijentima/kupcima. S tim u vezi, Standardom se zahteva prikazivanje informacija o priznatim prihodima po osnovu ugovora sa kupcima, početnim i krajnjim saldima potraživanja, imovine i obaveza koja se odnose na ugovore, ugovorene obaveze i trenutak njihovog ispunjenja, prosuđivanjima koja su korišćena za potrebe primene navedenog standarda, kao i priznatoj imovini na osnovu troškova zaključenja ili realizacije ugovora sa kupcima

Ključni cilj revizije prihoda jeste sticanje razumnog uveravanja da je računovodstveno obuhvatanje ovih transakcija konzistentno sa opšteprihvaćenim računovodstvenim principima i MSFI. Otuda je neophodno utvrditi da li su i na koji način priznati prihodi zasnovani na novom standardu i istovremeno osigurati da su sve pojedinačne transakcije poznate i razmotrene od strane revizora, budući da mišljenje revizora o kvalitetu finansijskih izveštaja može biti pod uticajem navedenih činjenica. Svakako prvi korak revizora odnosi se na razumevanje računovodstvenih zahteva koji se primenjuju u specifičnim okolnostima. Budući da je novi standard (MSFI 15) stupio na snagu tek prethodne godine (01.01.2018) izazovi sa kojima se revizori mogu suočiti u slučaju testiranja transakcija prihoda zasnovanih na ugovorima sa klijentima će se tek u narednim godinama objektivirati. Okolnost da trenutak kada je izvršeno priznavanje prihoda utiče na to da li su finansijski izveštaji oslobođeni materijalno značajnih grešaka i nepravilnosti ili je pak reč o postupcima kreativnog računovodstva, za revizora je od posebnog značaja da ustanovi da li je doslovno respektovan princip realizacije, odnosno da li su ispunjeni uslovi za priznavanje ove kategorije prihoda. Iz navedenog razloga revizor mora proći kroz sve faze modela za priznavanje prihoda koji je prezentovan u MSFI 15 i za svaki od navedenih koraka izvršiti odgovarajuće testiranje i pribavljanje dokaza. Naime, pogrešna primena MSFI 15 , značajno povećava revizorski rizik.

Revizorski rizik se kao što je poznato odnosi na donošenje pogrešnog zaključka o kvalitetu finansijskih izveštaja. To često slučaj kada menadžment entiteta stavlja prevelik akcenat na iskazani dobitak, zbog čega agresivno interpretira računovodstvene standarde (Knapp, 2016). Moguće manipulacije prihodima obuhvataju priznavanje fiktivnih prodaja, odnosno prikazivanje isporuka kupcima koje nikada nisu izvrešene, preuranjeno priznavanje prihoda, otpremanje nedovršenih proizvoda, kreiranje fiktivnih faktura, otpremanje robe kupcima koji nisu naručili robu, neadekvatno otpisivanje pozicije potraživanja i drugo (Mulford \& Comiskey, 2011).

Postupci revizije u vezi sa prihodima zasnovanim na ugovoru sa klijentima obuhvataju (American Institute of Certified Public Accountants, 2019): 


\section{Identifikovati ugovor sa kupcima da se isporuče proizvodi ili usluga}

Forma ugovora može biti pisana, usmena, ili implicirana poslovnom praksom klijenta, ali je važno da ugovor bude primenljiv (izvršni) i da ima komercijalnu suštinu. Neophodno je razmotriti sve relevantne činjenice i okolnosti kako bi se utvrdilo da li postoji ugovor, odnosno da li sporazum ispunjava definiciju ugovora. Revizor nadalje mora razmotriti da li su ugovorne strane prihvatile ugovor i da li su saglasne da izvrše definisane obaveze (Kovačević, Trandafilović, \& Kalač, 2019). U slučaju kada je ugovor zaključen usmeno ili se određena obaveza podrazumeva, neophodno je da se odgovarajućim revizorskim procedurama pribavi dokaz u pogledu ugovornih uslova. Tako, na primer, menadžment može razviti određenu politiku koja će reflektovati zahteve određenog tipa ugovora.

Dokaz o prihvaćenom ugovoru može zahtevati pribavljanje konfirmacije od klijenta u pogledu datuma zaključenja ugovora. Entiteti moraju pružiti revizoru dovoljno adekvatnih dokaza kako bi bio u mogućnosti da izvede zaključak o tome da li su strane privržene ugovoru. Takođe, neophodno je identifikovati sva prava koja su implicitno i eksplicitno sadržana u ugovoru. Na primer, praksa entiteta iz prethodnih godina može ukazati na implicitno pravo povrata robe od strane klijenta, iako je u ugovoru navedeno drugačije ili takva odredba nije uopšte uneta u ugovor.

Nadalje, neophodno je identifikovati uslove plaćanja za preneta dobra ili usluge. Ukoliko postoji značajna neizvesnost u pogledu rizika, vremenskog rasporeda ili iznosa budućih novčanih tokova, kao rezultat ugovornih odnosa, pretpostavke revizora u pogledu procenjenih prihoda postaju izazovnije. Utvrđivanje komercijalne suštine ugovora može zahtevati značajna prosuđivanja. Otuda revizor može imati potrebu da konsultuje pravne izvore kako bi rešio kompleksna pitanja.

\section{Utvrditi obaveze iz ugovora}

Ovaj korak, kao i prethodni, zahteva značajna prosuđivanja. Revizorske procedure usmerene su na razumevanje prirode ugovora, broja postojećih ugovora i kontrolu nad identifikovanim ugovornim obavezama. Time se pruža mogućnost da se definiše priroda narednih revizorskih procedura (ispitivanje dokumentacije, upiti, istraživanje osnovnih tvrdnji menadžmenta), kao i nivo sposobnosti i znanja neophodnih da se sprovedu testiranja u ovom području. Naime, nove vrste ugovora mogu inicirati nastanak novih problema sa kojima se revizor nije ranije suočavao.

Obaveze koje su navedene u ugovoru sa kupcima u pogledu prenosa dobra ili pružanja usluga mogu se identifikovati eksplicitno, ali se u određenim slučajevima obećanje o obezbeđenju dobara ili usluga može identifikovati posredno. Značaj navedenog identifikovanja sadržan je u činjenici da ugovorne obaveze predstavljaju osnovu za pravovremeno priznavanje prihoda.

\section{Odrediti cenu transakcije}

Revizor u ovoj fazi treba da razmotri procene menadžmenta u pogledu varijabilne komponente cene transakcije i prikupiti dokaze koje potvrđuju održivost pretpostavki na kojima je menadžment zasnovao procene. $S$ tim u vezi, neophodno je razmotriti da li su sagledani 
svi trendovi i okolnosti, da li su pretpostavke sveobuhvatne u smislu da su respektovani svi relevantni faktori, da li su iste podržane pouzdanim informacijama, obim pretpostavki i alternativa koje su razmatrane, kompromis u odnosu na kontradiktorne informacije prilikom izvođenja konačnog zaključka i drugo. Cilj je da se utvrdi da li su procene menadžmenta razborite i realne. Takođe, procena verovatnoće da li će doći do preokreta u iznosu priznatih kumulativnih prihoda zahteva razmatranje različitih scenarija, zavisno od tipa transakcije. Otuda mogu biti neophodni dodatni razgovori i diskusije sa menadžmentom za potrebe pribavljanja dodatnih informacija kada se vrši revizija navedenih procena.

\section{Alokacija transakcione cene na obaveze iz ugovora}

Alokacija transakcione cene na pojedine ugovorne obaveze se zasniva na prosuđivanju menadžmenta uz maksimalnu upotrebu uočljivih inputa. Sa druge strane, neophodno je da revizor evaluaciju navedenih procena zasniva na tržišnim uslovima i specifičnostima posmatranog entiteta.

\section{Priznavanje prihoda kada entitet ispuni obaveze}

Od posebnog značaja za ovu fazu, kao što je prethodno već istaknuto, jeste da li ispunjenje obaveza zahteva određeni vremenski period ili se pak obaveza izvršava u određenom trenutku. Ocena da li je u pitanju izmirenje obaveza tokom vremena zahteva procene i razmatranja brojnih kriterijuma. Kriterijum izvršnosti za pravo naplate (po osnovu izvršenih obaveza) zahteva da entitet meri progres u izvršenju obaveza tokom perioda. Otuda je na kraju svakog izveštajnog perioda neophodno prosuđivanje o stepenu dovršenosti transakcije. U slučaju kada se obaveze izvršavaju u određenom trenutku, prenosom kontrole na kupca neophodno je precizno ustanoviti koji je to trenutak, što zahteva prosuđivanje revizora, kao i analizu ugovora, pravnu interpretaciju (korišćenje usluga eksperata), kao i konfirmacije kupaca.

\section{Zaključak}

Prihodi po svom karakteru predstavljaju izazovnu kategoriju za reviziju s obzirom na visok rizik od manipulacija, kako bi se iskazao odgovarajući periodični rezultata. Uvođenjem MSFI 15 Prihodi od ugovora sa kupcima uvedene su značajne novine sa ciljem da se otklone nejasnoće koje su postojale u vezi sa priznavanjem i merenjem prihoda. Navedenim standardom tangirani su finansijski izveštaji entiteta u brojnim industrijama poput telekomunikacija, tehnologije, vojne industrije, vazduhoplovstva, intelektualne svojine i drugo. Za revizore navedeni standard znači dodatni izazov u smislu da neadekvatna primena standarda od strane entiteta klijenta, doprinosi povećanju revizorskog rizika. Pozicije prihoda podložne su inherentnom riziku u smislu da će prihodi biti priznati u neodgovarajućem obračunskom periodu. Kako bi navedeni rizik sveo na razumnu meru, revizor prilikom verifikacije pozicije prihoda mora sprovesti preliminarne analitičke procedure 
i druge postupke, kako bi pribavio dovoljan obim adekvatnih dokaza o tome da li je prilikom računovodstvenog obuhvatanja prihoda respektovano načelo realizacije, kao i zahtevi relevantnih računovodstvenih standarda. U navedenom procesu neophodno je da revizor primeni profesionalno prosuđivanje. Za pozicije prihoda koje se zasnivaju na ugovoru, revizor mora detaljno proći kroz sve faze modela za obuhvatanje prihoda koji je prezentovan u MSFI 15 i primeniti odgovarajuće revizorske procedure.

\section{Literatura}

[1] American Institute of Certified Public Accountants, (2019), Audit and Accounting Guide: Revenue Recognition, AICPA.

[2] Andrić, M., Krsmanović, B., \& Jakšić, D. 2004). Revizija: Teorija i praksa, Ekonomski fakultet, Subotica.

[3] Chartered Professional Accountants Canada (2015). IFRS 15 Revenue from Contract with Customers, pristupljeno https://www2.deloitte.com/content/dam/Deloitte/ca/Documents/audit/caen-your-questions-answered_IFRS\%2015_eFINAL\%20FINAL-s.pdf [28.04.2019].

[4] Gramling, A., Rittenberg, L., \& Johnstone, K. (2012). Auditing: A Business Risk Approach, South-Western Cengage Learning, Mason. Delhi.

[5] Gupta, K. (2006), Contemporary Auditing, McGraw-Hill Publishing Company Limited, New

[6] Johnstone, K., Gramling, A., \& Rittenberg, L. (2013). Auditing: A Risk Based Approach to Conducting a Quality Audit, South-Western Cengage Learning, Toronto. Boston.

[7] Knapp, M., (2016). Contemporary Auditing: Real Issues and Cases, Cengage Learning,

[8] Kovačević, M., Trandafilović, J., \& Kalač, D. (2019). Revizijski aspekt izvršenja budžeta. Oditor - časopis za Menadžment, finansije i pravo, 5(1), 93-105.

[9] Martić, S. (1993). Separati iz revizije, Ekonomski fakultet, Beograd.

[10] Milojević, D. (2006). Revizija finansijskih izveštaja, FTB, Beograd.

[11] Mirza, A., \& Holt, G. (2011). IFRS Practical Implementation Guide and Workbook, John Wiley and sons, New Jersey.

[12] Mulford C.W. \& Comiskey E.E: (2011). The financial number game: Detecting Creative Accounting Practices, John Wiley \& Sons, Inc., New York.

[13] Nešić, V. (2017). MSFI 15 - Prihodi po ugovorima sa kupcima, Računovodstvo, Savez računovođa i revizora Srbije, 61(1-2), 51-69.

[14] Novaković, S., Jovićević, P., \& Simin, M. (2018). Interna revizija u funkciji menadžmenta, Oditor - časopis za menadžment, finansije i pravo, Centar za ekonomska i finansijska istraživanja, 4(1), 63-84.

[15] Puttick, G., Van Esch, S., Van Esch, S.D., \& Kana, S. (2007), The Principles and Practites of Auditing Juta \& Co, Ltd, Cape Town.

[16] Ranković, J. (2016). Teorija bilansa, Ekonomski fakultet, Beograd.

[17] Škarić-Jovanović, K. (2013). Finansijsko računovodstvo, Ekonomski fakultet, Beograd. 